\title{
Mixed-up about how to diagnose and treat mixed features in major depressive episodes
}

\author{
Stephen M. Stahl \\ ISSUE: \\ The classical point of view - that major depressive episodes (MDEs), no matter \\ what additional symptoms are present, should be treated first line with anti- \\ depressants-is now giving way to new a notion. The idea is that MDEs mixed with \\ a few symptoms of mania/hypomania should be viewed very differently in terms of their \\ natural history, clinical outcome, and treatment, and perhaps certain antipsychotics \\ should be given as first-line treatment rather than antidepressant monotherapy.
}

\section{Take-Home Points}

- A paradigm shift is afoot for the prognosis and treatment of major depressive episodes (MDEs) accompanied by a few symptoms of mania/hypomania, but many questions persist.

- A debate is ongoing about how to define the number and type of manic/hypomanic symptoms in order to diagnose "MDEs with mixed features," a condition that may comprise up to one-half of all MDEs depending upon how many and which type of manic symptoms are included in the definition.

n The evidence base of studies on the treatment of MDEs with subthreshold manic/hypomanic symptoms is scant, and there are no FDA-approved treatments.

- Nevertheless, it is already clear that clinicians should always inquire about manic/hypomanic symptoms in all patients with MDEs, and no longer automatically view classical antidepressant monotherapy for first-line treatment of all MDEs. For many patients with MDEs plus subthreshold manic/hypomanic symptoms, antidepressants may be ineffective and may actually induce worsening of mania or suicidality in some patients. Instead of antidepressant monotherapy, certain atypical antipsychotics are evolving as best practice for first-line treatment options for many patients with MDEs mixed with subthreshold mania/hypomania.

\section{Introduction}

Historically, major depressive episodes have been treated-not surprisingly-with drugs known as antidepressants. ${ }^{1,2}$ The first shift away from this simple notion was the recognition that major depressive episodes (MDEs) in a patient with a prior manic episode may be better treated first with mood stabilizers and atypical antipsychotics rather than antidepressants. ${ }^{1,2}$ Now comes the question of how to manage MDEs when a few symptoms of mania/ hypomania are also present, whether or not there has been a past episode of mania or hypomania. ${ }^{2}$

\section{What's "a Little Bit of Mania?"}

In the Diagnostic and Statistical Manual of Mental Disorders, Fourth Edition (DSM-IV-TR), "mixed" meant full depressive syndrome plus full manic syndrome (Figure 1) ${ }^{3}$ and was treated the same as mania without depression. ${ }^{2}$ In the Fifth Edition (DSM-5), however, "mixed" now means 3 or more symptoms from a designated list (Table 1 and Figure 1). ${ }^{4}$ Controversy exists with this DSM-5 definition of mixed features, because even 1 or 2 symptoms of subthreshold mania/ hypomania increases the chance of a patient progressing to bipolar disorder, and half of patients with subthreshold manic/hypomanic symptoms have only 1 or 2 symptoms, not 3 or more. ${ }^{5}$ Are they not "mixed?" 


\section{BRAINSTORMS-Clinical Neuroscience Update}

\section{Figure 1. Conceptualization of pure and mixed states in DSM-IV-TR and DSM-5.}

\begin{tabular}{|c|c|c|c|c|c|}
\hline $\begin{array}{l}\text { Core } \\
\text { symptoms } \\
\text { Manic } \\
\text { Depressive }\end{array}$ & $\begin{array}{l}\text { Elevated } \\
\text { mood } \\
\geq 3 \\
<5\end{array}$ & \multicolumn{3}{|c|}{$\begin{array}{c}\text { Elevated mood }+ \\
\text { depressed mood or loss of interest } \\
\geq 3 \\
\geq 5\end{array}$} & $\begin{array}{l}\text { Depressed mood } \\
\text { or loss of interest } \\
\qquad 3 \\
\geq 5\end{array}$ \\
\hline $\begin{array}{l}\text { DSM- } \\
\text { IV-TR }\end{array}$ & Manic & & Mixed & & Depressive \\
\hline DSM-5 & Manic & Manic with mi & tures & $\begin{array}{l}\text { Depressive with } \\
\text { mixed features }\end{array}$ & Depressive \\
\hline $\begin{array}{l}\text { Core } \\
\text { symptoms } \\
\text { Manic } \\
\text { Depressive }\end{array}$ & $\begin{array}{c}\text { Elevated mood } \\
+ \text { energy } \\
\geq 3 \\
<5\end{array}$ & $\begin{array}{l}\text { Elevated mood } \\
+ \text { energy } \\
\geq 3 \\
\geq 3\end{array}$ & & $\begin{array}{l}\text { Depressed mood } \\
\text { or loss of interest } \\
\qquad 3 \\
\geq 3\end{array}$ & $\begin{array}{l}\text { Depressed mood } \\
\text { or loss of interest } \\
\qquad 3 \\
\geq 5\end{array}$ \\
\hline
\end{tabular}

\section{Table 1. DSM-5 Mixed Features Specifier}

Full criteria for a major depressive episode (MDE) and $>3$ of these manic symptoms:

Elevated, expansive mood

Inflated self-esteem or grandiosity

More talkative than usual or pressure to keep talking

Flight of ideas or racing thoughts

Increase in energy or goal-directed activity (socially, at work or school, or sexually)

Increased or excessive involvement in activities that have a high potential for painful consequences (eg, engaging in unrestrained buying sprees, sexual indiscretions, foolish business investments)

Decreased need for sleep

Furthermore, DSM-5 does not count 3 of the most common manic/hypomanic symptoms toward the mixed features diagnosis, namely the symptoms of irritability, distractibility, and psychomotor agitation, because they overlap with other disorders (eg, anxiety disorders) and with both mania and depression. ${ }^{4}$ However, several diagnostic criteria other than the DSM-5 do include these 3 symptoms, the argument being that excluding them will lead to misdiagnosis and inappropriate, if not dangerous, treatment strategies for those patients with MDEs who narrowly miss full DSM-5 criteria. $^{6-10}$ For example, 4 times as many patients are identified as having MDEs with mixed features using research diagnostic criteria than with the DSM-5. ${ }^{2}$ Imagine, for example, if we were to exclude psychosis as a diagnostic feature of schizophrenia because it overlaps with other disorders!

\section{Is Depression with “a Little Bit of Mania” Different?}

Patients who experience MDEs with subsyndromal manic/hypomanic symptoms have a younger age of onset of their depressive episodes, more episodes, higher comorbidity, and more suicide attempts, as well as other distinguishing characteristics (Table 2). ${ }^{11-13}$ The more symptoms you have, the more likely you are to progress to bipolar disorder, especially in the presence of psychosis. ${ }^{14}$ Perhaps the biggest difference between MDEs with and without mixed features is treatment response to antidepressants. ${ }^{15-20}$ That is, there is some evidence that certain antipsychotics may be effective for MDEs with mixed features, but no FDA approvals have been forthcoming yet (Table 3$).^{2}$ It is neurobiologically and psychopharmacologically plausible that mood stabilizers could be effective for MDEs with mixed features, but there is essentially no evidence for or against this theory (Table 4$).^{2}$ Finally, the existing evidence shows that antidepressant monotherapy either does not work or may even be harmful for patients with MDEs and mixed features. ${ }^{2}$

Overall, there is insufficient evidence for what to do for MDEs with mixed features from large scale, replicated, randomized, controlled trials, and 


\section{BRAINSTORMS-Clinical Neuroscience Update}

many troubling questions persist regarding the use of antidepressants in this condition. Therefore, we have organized and published a set of consensus guidelines from 20 experts from 7 countries on

\section{Table 2. Clinical Features Associated with Depression With}

Mixed Features

Family history of Bipolar disorder

Suicidality

Antidepressant-induced mania

Young age of onset

Long duration of illness

Poor prognosis

Severe depression

Antidepressant treatment resistance

Females

Comorbid anxiety

Comorbid SUD

Impulse control
4 continents on the treatment of MDEs with mixed features. $^{2}$

However, many important questions still remain: Do all atypical antipsychotics have efficacy? Will lithium and mood stabilizers eventually be proven to have efficacy? Is there a role for antidepressants in this condition? Is the use of antidepressant monotherapy in MDEs with mixed features a recipe for inducing mania, treatment-emergent activation syndrome, or suicidality? Does delay of effective treatment contribute to treatment resistance and poor outcomes? Answers to these questions will have to await evidence from largescale and replicated, randomized, controlled trials, some of which are in progress now.

\section{Do No Harm}

Like it or not, the clinician treating mood disorders is now immersed in a paradigm shift for the diagnosis and treatment for MDEs with mixed features (compare Figures 2 and 3). The first question to ask may be how to

Table 3. Atypical Antipsychotics for Mood Disorders including Mixed Features

\begin{tabular}{|c|c|c|c|c|c|}
\hline & $\begin{array}{l}\text { Evidence of } \\
\text { Efficacy in MDE } \\
\text { with mixed } \\
\text { features }\end{array}$ & $\begin{array}{l}\text { FDA-Approved } \\
\text { for Bipolar } \\
\text { Depression }\end{array}$ & $\begin{array}{l}\text { FDA-Approved } \\
\text { for Bipolar } \\
\text { Mania }\end{array}$ & $\begin{array}{l}\text { FDA-Approved } \\
\text { for Bipolar } \\
\text { Maintenance }\end{array}$ & $\begin{array}{l}\text { FDA-Approved } \\
\text { for Major } \\
\text { Depressive } \\
\text { Disorder }\end{array}$ \\
\hline Aripiprazole & & & $\nabla$ & $\nabla$ & $\nabla$ \\
\hline Asenapine & $\nabla$ & & $\nabla$ & & \\
\hline Lurasidone & $\nabla$ & $\nabla$ & & & \\
\hline Olanzapine & $\nabla$ & $\underset{\text { (with fluoxetine) }}{\nabla}$ & $\nabla$ & $\nabla$ & $\underset{\text { (with fluoxetine) }}{\nabla}$ \\
\hline Quetiapine & $\nabla$ & $\nabla$ & $\nabla$ & $\nabla$ & $\nabla$ \\
\hline Risperidone & & & $\nabla$ & $\nabla$ & \\
\hline Ziprasidone & $\nabla$ & & $\nabla$ & $\nabla$ & \\
\hline
\end{tabular}

Table 4. Mood Stabilizers in Mood Disorders including Mixed Features

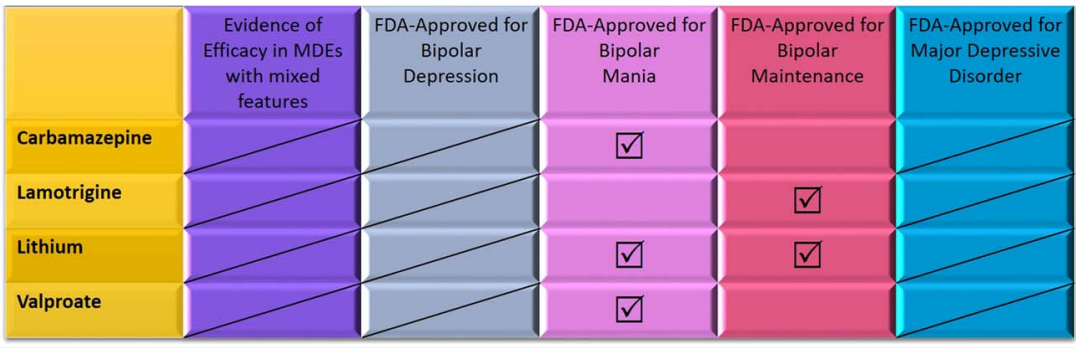




\section{BRAINSTORMS-Clinical Neuroscience Update}

Figure 2. Major depressive episodes: a whiff of depression means treat with an antidepressant?

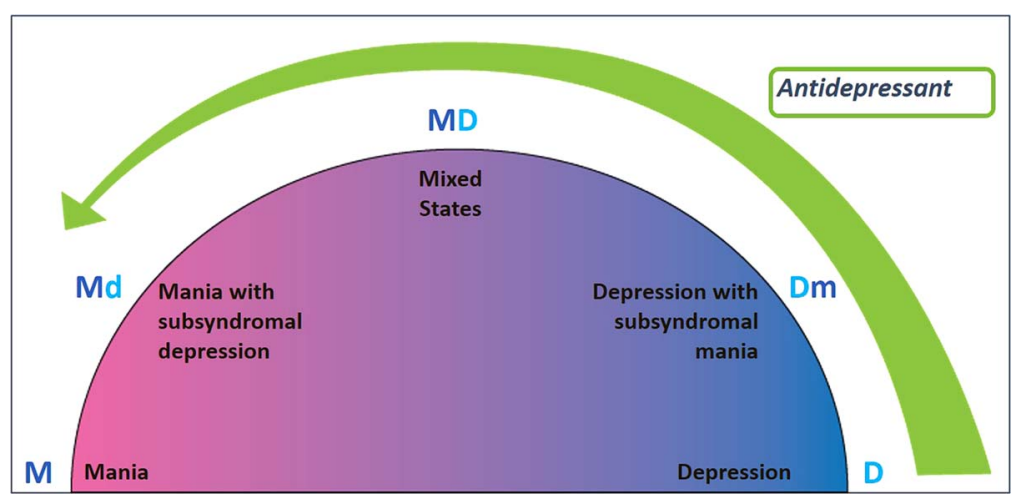

Figure 3. Major depressive episodes: a whiff of mania means treat with an antipsychotic?

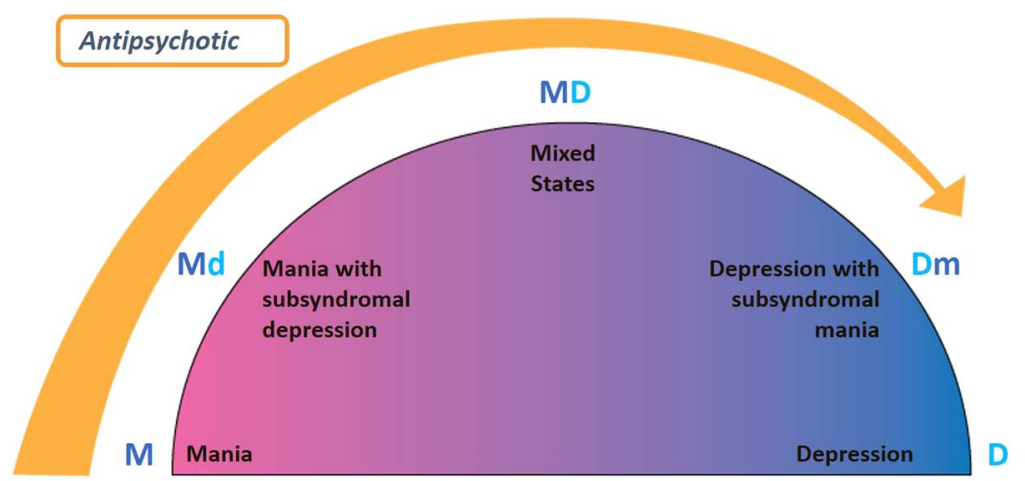

do no harm when treating patients now, while the data are unclear and more data are being generated. The answer may be to determine which is potentially more detrimental: misdiagnosing someone who is "pure unipolar" wrongly as MDE with mixed features and treating him or her wrongly with antipsychotics; or treating unidentified MDEs with mixed features wrongly with a sequence of several antidepressant monotherapies?

In the past, the paradigm seemed to be that "a whiff of depression" in a patient meant antidepressant monotherapy (Figure 2). This meant treating pure unipolar depression well, but treating unidentified MDEs with mixed features, perhaps wrongly, with antidepressant monotherapy. Is the paradigm now shifting to "a whiff of mania" means certain atypical antipsychotics get prescribed instead of antidepressant monotherapy? In this case, MDEs with mixed features are treated well, but those wrongly identified MDEs with mixed features get antipsychotics instead of antidepressants (Figure 3).

More precisely, the DSM-5 approach is to enhance specificity at the expense of sensitivity, and here "mixed" means 3 or more symptoms from a designated list (Table 1) that excludes 3 of the most common subthreshold manic/hypomanic symptoms, namely distractibility, irritability, and psychomotor agitation. In the case of the DSM-5 diagnosis of mixed features, there is $100 \%$ specificity (everybody really has mixed features by this definition), but only $5.1 \%$ sensitivity. ${ }^{7,9}$ So, all patients diagnosed will indeed have mixed features, but only $5.1 \%$ of individuals with mixed features will be identified. If the goal is impeccably accurate diagnosis, this is the way to go, particularly for research studies perhaps. However, in clinical practice, this means that $95 \%$ of individuals with mixed features are wrongly diagnosed without mixed features, and are at risk of receiving inappropriate or harmful treatment 


\section{BRAINSTORMS-Clinical Neuroscience Update}

Figure 4. One of the most important questions to ask any patient with depression.

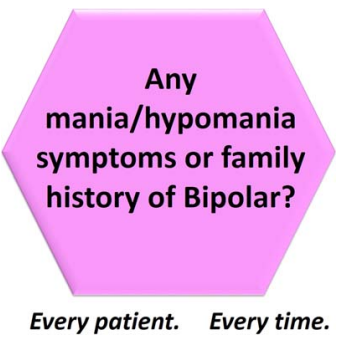

with antidepressant monotherapy rather than first line with certain atypical antipsychotics.

On the other hand, utilizing criteria that include distractibility, irritability, and psychomotor agitation for the diagnosis of mixed features, there is $87 \%$ specificity, but $55 \%$ sensitivity. ${ }^{7,9}$ That means in practice that $13 \%$ of patients identified with mixed features actually do not have it and might inappropriately get an atypical antipsychotic rather than antidepressant monotherapy. But, less than half of patients with mixed features are at risk of getting the wrong treatment. If diagnostic criteria were relaxed to allow just 1 or 2 symptoms of mania, there could be even greater sensitivity but a greater loss of specificity. Likely, clinicians will increasingly wish to treat mixed features appropriately with certain antipsychotics instead of antidepressant monotherapy, even if it means inadvertently treating pure unipolar depression too early with antipsychotics.

Whatever action a clinician takes, one thing is already clear (Figure 4). We now have a very important question to ask any patient with depression: Do you have any mania/hypomania symptoms and any family history of bipolar disorder?

Every patient. Every time.

\section{Acknowledgment}

The author wishes to thank Dr. Debbi A. Morrissette for her assistance in preparing the figures, tables, and references for this manuscript and for inspiring the author by collaborating on this project including the guidelines published in this special issue, her own editorial, and slide preparation for my lectures.

\section{References:}

1. Stahl SM. Stahl's Essential Psychopharmacology. 4th ed. New York: Cambridge University Press; 2014.
2. Stahl SM, Morrissette DA, Faedda G, et al. Guidelines for the recognition and treatment of mixed depression. CNS Spectr.

3. American Psychiatric Association. Diagnostic and Statistical Manual of Mental Disorders. 4th ed., text rev. Washington, DC: American Psychiatric Association; 2000.

4. American Psychiatric Association. Diagnostic and Statistical Manual of Mental Disorders. 5th ed., Washington, DC: American Psychiatric Association; 2013

5. Hu J, Mansur R, McIntyre RS. Mixed specifier for bipolar mania and depression: highlights of DSM-5 changes and implications for diagnosis and treatment in primary care. Prim Care Companion CNS Disord. 2014; 16(2): PCC.13r01599.

6. Koukopoulos A, Sani G. DSM-5 criteria for depression with mixed features: a farewell to mixed depression. Acta Psychiatr Scand. 2014; 129(1): 4-16.

7. Benazzi F. Reviewing the diagnostic validity and utility of mixed depression (depressive mixed states). Eur Psychiatry.. 2008; 23(1): 40-48.

8. Mahli GS, Lampe L, Coulston CM, et al. Mixed State discrimination: a DSM problem that won't go away? J Affect Disord. 2014; 158: 8-10.

9. Takeshima M, Oka T. DSM-5-defined 'mixed features' and Benazzi's mixed depression: which is practically useful to discriminate bipolar disorder from unipolar depression in patients with depression? Psychiatry Clin Neurosci. 2015; 69(2): 109-116.

10. Perugi G, Angst J, Azorin J-M, et al. Mixed features in patients with a major depressive episode: the BRIDGE-II-MIX study. J Clin Psychiatry. 2015; 76(3): e351-e358.

11. Akiskal HS, Benazzi F. Family history validation of the bipolar nature of depressive mixed states. J Affect Disord. 2003; 73(1-2): 113-122.

12. Angst J, Cui L, Swendsen J, et al. Major depressive disorder with subthreshold bipolarity in the National Comorbidity Survey Replication. Am J Psychiatry. 2010; 167(10): 1194-1201.

13. Goldberg JF, Perlis RH, Bowden CL, et al. Manic symptoms during depressive episodes in 1,380 patients with bipolar disorder: findings from the STEP-BD. Am J Psychiatry. 2009; 166(2): 173-181.

14. Fiedorowicz JG, Endicott J, Leon AC, Solomon DA, Keller MB, Coryell WH. Subthreshold hypomanic symptoms in progression from unipolar major depression to bipolar disorder. Am J Psychiatry. 2011; 168(1): 40-48.

15. Angst J, Cui L, Swendsen J, et al. Major depressive disorder with subthreshold bipolarity in the National Comorbidity Survey Replication. Am J Psychiatry. 2010; 167(10): 1194-1201.

16. Dudek D, Siwek M, Zielińska D, Jaeschke R, Rybakowski J. Diagnostic conversions from major depressive disorder into bipolar disorder in an outpatient setting: results of a retrospective chart review. J Affect Disord. 2013; 144(1-2): 112-115.

17. Sharma V, Khan M, Smith A. A closer look at treatment resistant depression: is it due to bipolar diathesis? J Affect Disord. 2005; 84(2-3): 251-257.

18. Rihmer Z, Gonda X. Antidepressant-resistant depression and antidepressant-associated suicidal behavioir: the role of underlying bipolarity. Depression Research and Treatment. 2011; 2011: 906462.

19. Amsterdam JD, Shults J. Does tachyphylaxis occur after repeated antidepressant exposure in patients with bipolar II major depressive episode? J Affect Disord. 2009; 115(1-2): 234-240.

20. Post RM, Leverich GS, Altshuler LL, et al. Relationship of prior antidepressant exposure to long-term prospective outcome in bipolar I disorder outpatients. J Clin Psychiatry. 2012; 73(7): 924-930. 